Tropical Journal of Pharmaceutical Research April 2016; 15 (4): 701-708

ISSN: $1596-5996$ (print); 1596-9827 (electronic)

(C) Pharmacotherapy Group, Faculty of Pharmacy, University of Benin, Benin City, 300001 Nigeria.

All rights reserved.

Available online at http://www.tjpr.org

Original Research Article

http://dx.doi.org/10.4314/tjpr.v15i4.5

\title{
Impaired reverse cholesterol transport and hepatic steatosis contribute to pathogenesis of high fat diet- induced hyperlipidemia in murine models
}

\author{
Xiaohui ZXH Zeng ${ }^{1,2}$, Dongmei SDM Sun ${ }^{1,2 \star}$, Nan YN Yao ${ }^{1,2}$, Yuxing CYX \\ Chen $^{1,2}$, Dake CDK Cai ${ }^{1,2}$, Xuejun HXJ Huang ${ }^{1,2}$, Dane HDE Huang ${ }^{1,2}$, Haining \\ GHN Gan $^{1,2}$, Qiaohuang ZQH Zeng ${ }^{1,2}$, Jingyu ZJY Zhao ${ }^{1,2}$ and Lin HL Huang ${ }^{1,2}$ \\ ${ }_{1}^{1}$ Guangdong Province Engineering Technology Research Institute of Traditional Chinese Medicine, ${ }^{2}$ Guangdong Provincial Key \\ Laboratory of Research and Development in Traditional Chinese Medicine, Guangzhou, Guangdong 510095, PR China
}

*For correspondence: Email: tcmgdp@163.com; Tel: +86-20-83482683; Fax: +86-20-83590979

\begin{abstract}
Purpose: To investigate the pathogenesis of high fat diet (HFD)-induced hyperlipidemia (HLP) in mice, rats and hamsters and to comparatively evaluate their sensitivity to HFD.

Methods: Mice, rats and hamsters were fed with high-fat diet formulation (HFD, $n=8)$ or a control diet (control, $n=8$ ) for 4 weeks. Changes in body weight, relative liver weight, serum lipid profile, expressions of hepatic marker gene of lipid metabolism and liver morphology were observed in three hyperlipidemic models.

Results: Elevated total cholesterol (TC), triglyceride, low density lipoprotein-cholesterol (LDL-C) and high density lipoprotein-cholesterol (HDL-C) levels and body weight were observed in all hyperlipidemic animals $(p<0.05)$, while hepatic steatosis was manifested in rat and hamster HLP models, and increased hepatic TC level was only seen $(p<0.05)$ in hamster HLP model. Suppression of HMG-CoA reductase and up-regulation of lipoproteinlipase were observed in all HFD groups. Hepatic gene expression of LDLR, CYP7A1, LCAT, SR-B1, and ApoA I, which are a response to reverse cholesterol transport (RCT), were inhibited by HFD in the three models. Among these models, simultaneous suppression of HMG-CR, LCAT, LDLR and SR-BI and elevated LPL were features of the hamster model.

Conclusion: As the results show, impaired RCT and excessive fat accumulation are major contributors to pathogenesis of HFD-induced murine HLP. Thus, the hamster model is more appropriate for hyperlipidemia research.
\end{abstract}

Keywords: Hyperlipidemic model, Murine, Hamster, mRNA, Reverse cholesterol transport, High-fat diet, Pathogenesis

Tropical Journal of Pharmaceutical Research is indexed by Science Citation Index (SciSearch), Scopus, International Pharmaceutical Abstract, Chemical Abstracts, Embase, Index Copernicus, EBSCO, African Index Medicus, JournalSeek, Journal Citation Reports/Science Edition, Directory of Open Access Journals (DOAJ), African Journal Online, Bioline International, Open-J-Gate and Pharmacy Abstracts

\section{INTRODUCTION}

Hyperlipidemia (HLP) is a disorder of lipid metabolism characterized by abnormally elevated levels of one or more lipids and/or lipoproteins in the blood [1], which has been identified as a clinical risk factor for atherosclerosis and cardiovascular disease [2]. Moreover, it is one of the major predisposing factors for cancer [3] and diabetes [4]. In the United States, approximately one of six adults suffers from hyperlipidemia [5]. Therefore, it is necessary to investigate pathogenesis of HLP 
and to find effective hypolipidemic agents. Since animal model of HLP plays a critical role in mimicking the disease pathogenesis for human HLP as well as evaluating hypolipidemia agents, multiply animal models have been extensively explored.

Although the pathogenesis of hyperlipidemia is multifactorial, which resulted to complex interactions between genetic, dietary and environmental factors, excessive absorption of lipids from a high-fat diet (HFD) or abnormal lipid metabolism in the body is one of the major contributing factors of hyperlipidemia [6]. Therefore, in the last ten years HFD-induced hyperlipidemic animal models have been commonly used worldwide. It is well documented that rats [7], mice [8], rabbits [9], guinea pig [10], hamster [11], and gerbil [12] are used for modeling human HLP. Among them, rats, hamster and mice are the most extensively used animals [13-19]. However, the molecular basis of pathogenesis in hyperlipidemic rats, hamster and mice model induced by HFD remain unclear, which limits its predictability and accuracy on evaluating lipid-lowering agents for human HLP.

In recent years, a larger number of innovative lipid-lowering agents have emerged, including PSCK9 inhibitor and LXR $\beta$ agonist, but it remains questionable whether these routine animal models will be suitable for evaluating new-target agents. Undoubtedly, elucidating the molecular mechanism of generally used animal model will facilitate evaluation of new lipidlowering agent. Based on preliminary optimization of the HLP model in our laboratory and wide investigation of literature, modified HFD formulation containing bile acid and propylthiouracil is chosen for this research, in which rational time frame and efficiency of modeling is taken into consideration. Therefore, our studies focused on re-evaluating HFDinduced hyperlipidemic animal models by assessing hepatic marker genes of lipid metabolism in combination with investigating serum lipid profile and morphology of liver tissues.

\section{EXPERIMENTAL}

\section{Ethical issues}

All animal experimental protocols were approved by the Animal Ethics Committee of Guangdong Provincial Engineering Technology Institute of Traditional Chinese Medicine (Guangzhou, Guangdong, China) (no. LN:SYXK2010-0059).
The care and treatment of the animals were conducted in accordance with the guidelines (Publication no. 85-23, revised 1996) provided by the National Institute of Health (Bethesda, MA, USA) and U.S. Department of Agriculture (Washington, DC, USA).

\section{Materials}

Total cholesterol(TC), triglyceride (TG), highdensity lipoprotein cholesterol (HDL-C), lowdensity lipoprotein cholesterol (LDL-C) kits were purchased from Nanjing Jiancheng Bioengineering Institute (Nanjing, Jiangsu, China). Ethanol and isopropanol of analytical grade were purchased from Dikma Technologies, Inc. (Beijing, China). TRIzol® reagent was purchased from Invitrogen Life Technologies (Carlsbad, CA, USA). The RevertAid ${ }^{\mathrm{TM}}$ First Strand cDNA Synthesis kit and the Maxima ${ }^{\mathrm{TM}}$ SYBR-Green/Fluorescein qPCR Master mix $(2 \times)$ were purchased from Thermo Fisher Scientific (Burlington, ON, Canada).

\section{Animals, diets and treatments}

Twenty male Sprague-Dawley (SD) rats weighing between 180 and $220 \mathrm{~g}$, and twenty male $\mathrm{NIH}$ mice weighing between 18 and $22 \mathrm{~g}$ were purchased from the Guangdong Medical Laboratory Animal Center (Guangzhou, Guangdong, China) (nos. 44007200015094 and 44007200015095), and twenty male golden hamster weighing between 120 and $150 \mathrm{~g}$ were purchased from Vital River Laboratory Animal Technology Co. Ltd. (no. 11400700071275).

All animals were kept in a specific pathogen free room under controlled conditions. A 12 h lightdark cycle was maintained, with lights on between 7:00 am and 7:00 pm, and the temperature was maintained at $24 \pm 1{ }^{\circ} \mathrm{C}$. The animals were provided with standard laboratory diet and tap water and allowed to adapt to the environment for 1 week prior to the start of the experiment. Afterward, the rats, mice and hamster were randomly divided into two groups with ten animals in each group. The animals in the normal control (NC) group were fed on a normal diet, while animals in the model group were fed with a high-fat diet (standard diet +15 $\%$ lard $+5 \%$ cholesterol $+0.4 \%$ bile salt +0.5 $\%$ propylthiouracil) by intragastic administration once per day, $20 \mathrm{~mL} / \mathrm{kg}$ mice body weight, and $10 \mathrm{~mL} / \mathrm{kg}$ rat and hamster body weight for 4 weeks. Then the animals were anesthetized in a $10 \%$ chloral hydrate and the blood and livers were collected. 
At the end of the experiment, all feed were removed $12 \mathrm{~h}$ before euthanization. Blood was collected into the centrifuge tube from the abdominal aorta and left to coagulate at room temperature. The serum samples were obtained by centrifugation at $3,300 \mathrm{~g}, 4{ }^{\circ} \mathrm{C}$ for $10 \mathrm{~min}$ and stored at $4{ }^{\circ} \mathrm{C}$ for further analysis.

The whole liver from each animal was immediately removed, washed with PBS, dried on filter paper, weighed and a slice of each sample was stored at $80{ }^{\circ} \mathrm{C}$ for further analysis.

\section{Measurement of Lipid Levels in the serum and liver}

The PCR primers used are listed in Table 1. The serum and liver levels of TC, TG, HDL-C and LDL-C were determined using the respective assay kits in accordance with the manufacturer's instructions. All samples were detected using the 722 Grating Spectrometer (Shanghai Cany Precision Instrument, Co., Ltd., Shanghai, China).

\section{Quantitative PCR (qPCR) analysis of hepatic mRNA levels}

Total RNA was extracted from the liver samples using TRIzol reagent in accordance with the manufacturer's instructions. A total of $3 \mu \mathrm{g}$ of total RNA was reverse - transcribed into cDNA using the First Strand cDNA Synthesis kit at 42 ${ }^{\circ} \mathrm{C}$ for $1 \mathrm{~h}$. qPCR was performed using the $\mathrm{iQ} 5^{\mathrm{TM}}$ real-time PCR detection system (Bio-Rad, Hercules, CA, USA) and performed in a reaction mix containing $1 \mu \mathrm{L}$ cDNA,

Table 1: Primers for real-time RT-PCR

\begin{tabular}{|c|c|c|c|}
\hline Gene & Forward Primer & Reverse Primer & $\begin{array}{l}\text { Product } \\
\text { (bp) }\end{array}$ \\
\hline \multicolumn{4}{|l|}{ Mouse } \\
\hline $\mathrm{ABCA} 1$ & 5'-GTGGTGTTCTTCCTCATTACTG-3' & $\begin{array}{l}\text { 5'-ATCCTCATCCTCGTCATTCAA- } \\
\text { 3' }\end{array}$ & 102 \\
\hline ApoAl & 5'-GTATGGCAGCAAGATG-3' & 5'-AGGAGATTCAGGTTCAG-3' & 149 \\
\hline CYP7A1 & 5'-TTCTCAACGATACACTCT-3' & 5'-СТССАТTСАСТTCTTCAG-3' & 168 \\
\hline HMG-CR & 5'-GGACCAACCTTCTACCTCAG-3' & 5'-CTCACCAGCCATCACAGT-3' & 128 \\
\hline LCAT & 5'-CCGCACCCTATGACTG-3' & 5'-CAAGGCTATGCCCAAT-3' & 126 \\
\hline LDLR & 5'-TGATGGAGACCGAGATTG-3' & 5'-GCTGCGATGGATACACT-3' & 259 \\
\hline SR-B1 & 5'-TTCTACTTGTCTGTCTACT-3' & 5'-GGTGTCGTTGTCATTG-3' & 144 \\
\hline LPL & 5'-TGGCTCCAGAGTTTGA-3' & 5'-TTGAAGTGGCAGTTAGAC-3' & 170 \\
\hline $18 \mathrm{~S}$ & 5'-ACGGCTACCACATCC-3' & 5'-CAGACTTGCCCTCCA-3' & 162 \\
\hline \multicolumn{4}{|c|}{ 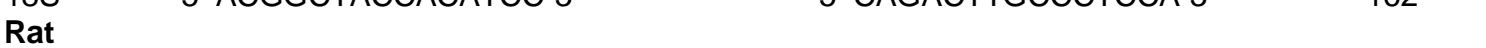 } \\
\hline ABCA1 & 5'-CAGCAACTACAGTGGCGGTAACA-3' & $\begin{array}{l}\text { 5'- } \\
\text { AATGCTTAGGGCACAATTCCACA- } \\
3^{\prime}\end{array}$ & 145 \\
\hline ApoAl & 5'-AAGGCATCTAAAGGTTGT-3' & 5'-TCAGGGTAGGGTGGTT-3' & 149 \\
\hline CYP7A1 & 5'-TGCCGTGTTGGTGAG-3' & 5'-TTCGCAGAAGTAGTGTAAT-3' & 291 \\
\hline HMG-CR & 5'-TGACGCTCTGGTGGA-3' & 5'-GTTACTGGGTTTGGTTTAT-3' & 249 \\
\hline LCAT & 5'-GCTACCGAAAGACAGAGG-3' & 5'-CCAAAGCCAGGGACA-3' & 163 \\
\hline LDLR & 5'-CAGACCCAGAGCCATCGTAGTG-3' & $\begin{array}{l}\text { 5'-GTCACCAGAGAGTAGATGTCTAC } \\
3^{\prime}\end{array}$ & 120 \\
\hline SR-B1 & 5'-TACTTGTCCGTCTACT-3' & 5'-CGTGTCATT GTCATTG-3' & 141 \\
\hline LPL & 5'-TGGCTCCAGAGTTTGA-3' & 5'-TTGAAGTGGCAGTTAGAC-3' & 170 \\
\hline $18 \mathrm{~S}$ & 5'-ACGGCTACCACATCC-3' & 5'- CAGACTTGCCCTCCA-3' & 162 \\
\hline \multicolumn{4}{|l|}{ Hamster } \\
\hline $\mathrm{ABCA} 1$ & 5'-GGTGTTCTTCCTCATTA-3' & 5'-GGTGTTCTTCCTCATTA-3' & 193 \\
\hline ApoAl & 5'-CGTGGCTGTGCTCT-3' & 5'-GCCGCTGTCTTTCA-3' & 127 \\
\hline CYP7A1 & $\begin{array}{l}\text { 5'- } \\
\text { TACTAGATAGCATCATCAAGGAGGCTC- } \\
3^{\prime}\end{array}$ & $\begin{array}{l}\text { 5'-CCATCCTCAAGGTGCAGAGTG- } \\
\text { 3' }\end{array}$ & 97 \\
\hline HMG-CR & 5'-GGGCAATAGGTCTT-3' & 5'-ACTGGAAACGGATG-3' & 234 \\
\hline LCAT & 5'-TTAGACGACAACAAG-3' & 5'-TAGGCAGCATACAT-3' & 179 \\
\hline LDLR & 5'-TGGTCATCCTCCTTGT-3' & 5'-TCTTCCGTGGTCTTCT-3' & 109 \\
\hline SR-B1 & 5'-TGAGAAGCCAATAGTG-3' & 5'-AAGACCAGAATGTTAGG-3' & 183 \\
\hline LPL & 5'-TGACGGAGGAAGAGATT-3' & 5'-TGCTGTGGTTGAAGTG-3' & 134 \\
\hline $18 \mathrm{~S}$ & 5'-TCTATGAGGGCTACGC-3' & 5'-CAGGGAGGAAGAGGAT-3' & 215 \\
\hline
\end{tabular}

Gene symbols: HMG-CR, HMG-CoA reductase; CYP7A1, cholesterol 7a-hydroxylase; ABCA1, ATP-binding cassette transporterA1; LCAT, lecithin cholesterol acyltransferase; ApoA I, apolipoproteinAI; SR-B1, scavenger receptorB1; LDLR, low-density lipoprotein receptor; LPL, lipoproteinlipase 
$12.5 \mu \mathrm{L} \quad$ Maxima $^{\mathrm{TM}} \quad$ SYBR-Green/Fluorescein qPCR Master mix $(2 \times), 1 \mu \mathrm{M}$ forward primer and $1 \mu \mathrm{M}$ reverse primer in a total volume of $25 \mu \mathrm{L}$. The cDNA was amplified using specific primers under the following conditions for 45 cycles: 94 ${ }^{\circ} \mathrm{C}$ for $30 \mathrm{~s}$, an annealing temperature of $55{ }^{\circ} \mathrm{C}$ for $30 \mathrm{~s}$ and then $72{ }^{\circ} \mathrm{C}$ for $50 \mathrm{sec}$, with a final incubation at $72{ }^{\circ} \mathrm{C}$ for $7 \mathrm{~min}$. The products were analyzed using the $C T$ value and all values were normalized against the 18S mRNA level. The final result was calculated using the $2-\Delta \Delta C t$ method.

\section{Histopathological examination}

Liver samples were resected and fixed with $10 \%$ formaldehydephosphate buffer saline (PBS, $\mathrm{pH}=$ 7.4), and embedded in paraffin, sectioned, stained with hematoxylin/eosin (HE) and analyzed by microscopy and morphometry.

\section{Statistical analysis}

All continuous variables were expressed as mean $\pm S D(n=8)$, and analyses were performed with SPSS software, version 15.0 (SPSS Science, Chicago, IL, USA). Statistical significance among groups was evaluated with One Way ANOVA (Dunnett's significant post-hoc test for pairwise multiple comparisons). Where linear regression was used, $p<0.05$ was considered statistically significant.

\section{RESULTS}

\section{Growth parameters of hyperlipidemia animals fed on a high fat diet}

As demonstrated in Table 2, no significant difference between NC and model subgroups were found in the initial body weight, final body weight, body weight gain and relative liver weight coefficient respectively in groups of mice, rats or hamsters.

\section{Influence on serum and liver lipid levels of three murine models}

As the results in Table 3 show, serum levels of TC, TG were raised, whereas HDL-C, LDL-C, and liver lipid levels of TC, TG were slightly changed in mice HFD group. In rats model, serum TC, TG, HDL-C and LDL-C are increased by HFD with statistically significant $(p<0.01)$, and liver TC and TG remain unchanged. In hamster model, the TC, TG, LDL-C and HDL-C level in serum were markedly elevated. In addition, hepatic TC and TG level were significantly raised in hamster HLP models $(p<$ 0.01).

Table 2: Growth parameters of all groups

\begin{tabular}{|c|c|c|c|c|c|c|}
\hline \multirow[t]{2}{*}{ Parameter } & \multicolumn{3}{|c|}{ Mice } & \multicolumn{2}{|r|}{ Hamsters } & \multirow[b]{2}{*}{ Model } \\
\hline & NC & Model & NC & Model & NC & \\
\hline $\begin{array}{l}\text { Initial body } \\
\text { weight (g) }\end{array}$ & $21.02 \pm 0.98$ & $20.88 \pm 1.04$ & $208.5 \pm 11.72$ & $207.96 \pm 11.79$ & $136.88 \pm 7.64$ & $134.97 \pm 6.76$ \\
\hline $\begin{array}{l}\text { Final body } \\
\text { weight }(\mathrm{g})^{\#}\end{array}$ & $38.06 \pm 2.08$ & $37.23 \pm 3.15$ & $308.44 \pm 25.63$ & $304.12 \pm 17.38$ & $180.20 \pm 10.50$ & $176.77 \pm 15.32$ \\
\hline $\begin{array}{l}\text { Body weight } \\
\text { gain }(\mathrm{g})\end{array}$ & $17.04 \pm 2.38$ & $16.35 \pm 3.26$ & $99.94 \pm 28.81$ & $96.16 \pm 12.70$ & $43.32 \pm 8.36$ & $41.8 \pm 13.98$ \\
\hline $\begin{array}{l}\text { Relative liver } \\
\text { organ coefficient } \\
(\%)\end{array}$ & $4.54 \pm 0.29$ & $4.71 \pm 0.48$ & $3.78 \pm 0.48$ & $3.51 \pm 0.23$ & $3.56 \pm 0.23$ & $3.45 \pm 0.31$ \\
\hline
\end{tabular}

The results are presented as the mean $\pm S D(n=10)$. ${ }^{*}$ Body weight at the beginning of the 4-week fed by high-fat-diet period.

\# Body weight at the end of the 4-week fed by high-fat-diet period

Table 3: Lipids and lipoproteins levels in HFD-induced hyperlipidemia models

\begin{tabular}{|c|c|c|c|c|c|c|}
\hline \multirow[t]{2}{*}{ Lipid } & \multicolumn{2}{|c|}{ Mice } & \multicolumn{2}{|c|}{ Rats } & \multicolumn{2}{|c|}{ Hamsters } \\
\hline & NC & Model & NC & Model & NC & Model \\
\hline Serum lipids & & & & & & \\
\hline $\mathrm{TC}(\mathrm{mmol} / \mathrm{L})$ & $2.87 \pm 0.42$ & $4.14 \pm 0.94 b$ & $1.81 \pm 0.33$ & $4.17 \pm 0.85 b$ & $5.11 \pm 0.96$ & $20.65 \pm 10.49 b$ \\
\hline TG (mmol/L) & $0.46 \pm 0.20$ & $0.92 \pm 0.22 a$ & $0.64 \pm 0.34$ & $1.51 \pm 0.35 b$ & $2.50 \pm 0.19$ & $6.42 \pm 4.92 b$ \\
\hline$H D L-C(\mathrm{mmol} / \mathrm{L})$ & $2.11 \pm 0.60$ & $2.72 \pm 0.95$ & $0.81 \pm 0.24$ & $1.65 \pm 0.81 b$ & $5.20 \pm 1.41$ & $9.56 \pm 3.23 b$ \\
\hline $\begin{array}{l}\text { LDL-C (mmol/L) } \\
\text { Liver lipids }\end{array}$ & $1.14 \pm 0.21$ & $1.44 \pm 0.55$ & $1.63 \pm 0.66$ & $2.36 \pm 0.90 b$ & $3.61 \pm 1.34$ & $8.21 \pm 3.75 b$ \\
\hline $\mathrm{TC}(\mathrm{mmol} / \mathrm{L})$ & $3.06 \pm 0.84$ & $3.59 \pm 0.82$ & $0.51 \pm 0.12$ & $0.76 \pm 0.61$ & $0.19 \pm 0.04$ & $1.02 \pm 0.48 b$ \\
\hline $\mathrm{TG}(\mathrm{mmol} / \mathrm{L})$ & $0.57 \pm 0.36$ & $1.08 \pm 0.27 b$ & $2.26 \pm 0.74$ & $2.18 \pm 0.95$ & $0.08 \pm 0.02$ & $0.23 \pm 0.11 b$ \\
\hline
\end{tabular}

The results are presented as the mean \pm standard deviation obtained from ten mice in each group. All values are expressed as mean \pm SEM $(n=10) ; a_{p}<0.05, b_{p<0.01}$ compared to the NC, normal control; Model, feed by high-fat diet; TC, total cholesterol; TG, triglyceride; HDL-C, high-density lipoprotein cholesterol; LDL-C, low-density lipoprotein cholesterol 
Expression on the hepatic mRNA levels of 3 murine models fed with HFD

The qPCR analysis was performed to measure the mRNA levels of hepatic genes of each model (Fig. 1). Compared with NC group, significant decrease were demonstrated in HMG-CR, CYP7A1, LCAT, and ApoAl mRNA levels in all model groups. In mice models, CYP7A1 mRNA levels were remarkably reduced in mice HLP model, whereas SR-BI, LDLR and ABCA1 were not affected by HFD. In the rat HLP model, expression of hepatic LDLR is suppressed by HFD, and mRNA level of LPL is slightly inhibited. In hamster model, it is noticeable that significant increase of LPL (12-fold $p<0.01)$ and decrease of HMG-CR, LCAT, ABCA1, LDLR $(p<0.05)$ and
SR-BI $(p<0.05)$ mRNA levels were observed while compared with normal control.

\section{Histopathological changes in hyperlipidemic rats and hamsters}

A lot of lipid droplets were observed in the cytoplasm of centrilobular hepatocytes in livers from HFD-fed rats and hamsters, compared with those from animals fed a normal diet (Figure $2 \mathrm{~b}$ and $d$ ). The variation of size of hepatocyte significantly increased after long-term administration of HFD and the nucleus shrinkage presented. Liver cells show vacuolar degeneration and microvesicular fatty change in the HFD groups, which is more severe in the hamster liver (Figure 2d).

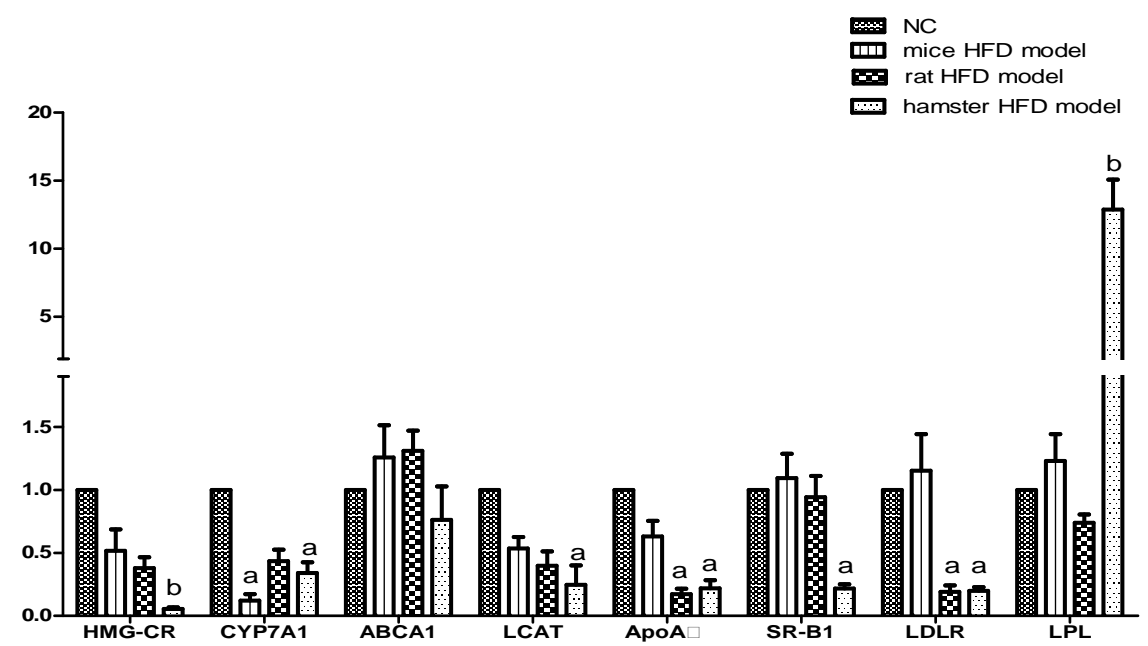

Figure 1: Analysis of hepatic mRNA levels using quantitative polymerase chain reaction in 3 HLP model groups. The $18 \mathrm{~S}$ gene was used as an internal control. Relative mRNA levels are presented as the mean \pm standard deviation obtained from eight animals in each group; ${ }^{\mathrm{a}} p<0.05,{ }^{\mathrm{b}} p<0.01$, vs. NC group. NC, normal control (See Tables 1 - 3 for the key to abbreviations and sequences of the primers used)
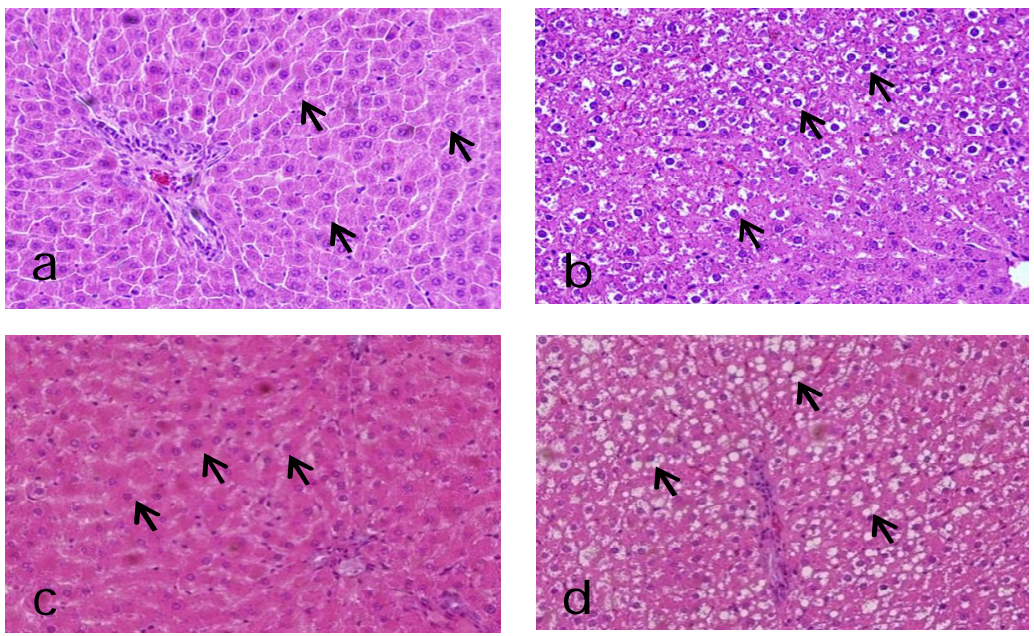

Figure 2: Pathological section ( HE staining) from rats or hamsters liver of hyperlipidemia.( a ) NC, normal control of rats; ( b ) rats model fed by high-fat-diet; ( c ) NC, normal control of hamsters; ( d ) hamsters model fed by high-fat-diet. All images are shown at $200 \times$ magnification 


\section{DISCUSSION}

In the present study, we used modified HFD, which is based on routine formulation, to induce 3 different murine hyperlipidemia (HLP) models. Compared with normal diet fed animals, a dramatic increase in serum TC, TG and LDL-C levels was observed (in Table 1) in 3 HLP models, and histopathological examination revealed evidently severe hepatic steatosis in the rat and hamster HFD-induced groups, indicating that HLP were successfully induced via 4-week administration of HFD in SD rats, NIH mice and hamster. Furthermore, hepatic steatosis, which is caused by long-term exposure to excessive fat in rat and hamster HLP models, represents the presence and the degree of metabolic dysfunction [20] in these models. Moreover, different expressive amount of RCT maker genes is responsible for the various HFD-induced phenotypic outcomes of 3 kinds of murine models.

LDL and HDL are two kinds of lipoproteins in RCT, which are essential for whole-body cholesterol homeostasis maintenance. As the result presented, the alteration of mRNA level of RCT marker genes was highly associated with the changing value of serum LDL and HDL, which showed in all HFD models. Specifically, hepatic LDLR and SR-BI are two major membrane receptors responsible for uptake of serum LDL and HDL, which are a response to lipid metabolism and elimination. According to the result, neither LDLR nor SR-BI were affected by HFD in mice model, however, only LDLR was affected by HFD in rat model and both genes were dramatically inhibited by HFD in hamster HLP model. Given that serum LDL is the endogenous ligands of the LDLR and SR-BI, simultaneous decline of two transporters raises serum LDL content by blocking their transportation from blood to liver in the hamster model, which renders hamster more vulnerable in response to HFD. Moreover, HDL, whose formation is promoted by catalytic action of lecithin-cholesterol acyltransferase (LCAT) and is constructed with ApoA I, is protective factor for human HLP. Considering the decrease of LCAT and ApoA I but increase HDL concentration in hamster model, immature or dysfunctional HDL may be overly produced without eliminating cholesterol from blood. In summary, the research finding strongly supported that hamsters are more vulnerable to HFD-induced hyperlipidemia and possesses priority in mimicking hyperlipidemia of human [21]. In other words, simultaneous decline of LDLR, SR-BI, ApoA $I$ and LCAT and increase dysfunctional HDL sensitize hamsters to HFD-induced hyperlipidemia. Moreover, histopathological changes in HLP hamsters indicate that long-term exposure of HFD may cause severe hepatic steatosis. Given that hepatic steatosis can cause down-regulation of LDLR and SR-BI, and consequent HLP [22], the remedy for hepatic steatosis should be considered for preventing and curing HLP. Therefore, it is worthy to explore further mechanism of interaction between hepatic steatosis and LDLR, SRBI and LCAT, which is potential to find new therapeutic target for HLP.

CYP7A1 is a liver specific enzyme that catalyzes the rate-limiting step in the biosynthesis of bile acid from cholesterol [23], and hepatic free cholesterol, which is released from HDL and LDL in RCT. Moreover, cholesterol necessarily undergoes this CYP7A1-induced conversion for further excretion. Thus, it is an important pathway for the elimination of cholesterol from the body. In our research, significant decline of CYP7A1 was observed in all the model groups, which indicates that hyperlipidemia is caused by hurdling elimination of hepatic HDL and LDL [24]. Noticeably, CYP7A1 of mice model shows more sensitive than two others in response to HFD. CYP7A1 is predominantly governed by nuclear receptor farnesoid $X$ receptor $(F X R)$ in mice, whereas it is dually mediated by FXR and LXR in rat and hamster which may guarantee stability of CYP7A1 in response to HFD. Therefore, CYP7A1 is more vulnerable to HFD in mice model. These results indicate mice HLP model is more valuable to evaluate the FXR agonist.

HMG-CoA reductase (HMG-CR) is a rate-limiting enzyme in cholesterol synthesis which was confirmed through chemical and genetic methods to be a validated drug target for statins in $S$. mansoni [25]. The present study demonstrated that the mRNA expression of HMG-CR in all model groups were inhibited due to excessive absorption of exogenous cholesterol. Lipoprotein lipase (LPL), an enzyme bound to the capillary endothelium, hydrolyzes TGs in TG-rich plasma lipoproteins (TRLs). LPL also plays a role in HDL maturation by providing surface material from chylomicrons (CM) and VLDL during TG hydrolysis. In our investigation, there is no significant difference of LPL mRNA expression in mouse and rat groups, but the dramatic induced expression of LPL was observed in hamster, suggested that up-regulated of LPL may be mediated by increase of serum LDL. To confirm correlation between LPL or HMG-CR and HLP in hamster model, more study on their activity is needed. Unfortunately, the present study did not measure their activity, this correlation cannot be further explained. 


\section{CONCLUSION}

The findings of this study evidently reveal that the pathogenesis of HFD-induced hyperlipidemia in murine models tightly correlate with impairment of RCT and hepatic steatosis, but it is unlikely that abnormal synthesis of endogenous cholesterol is engaged based on the decline of HMG-CR. In addition, HFD-induced HLP hamster model has priority in mimicking human HLP due to its similarity of phenotypic and genotypic alteration with human HLP. Based on the present findings, HFD-induced HLP hamster model is promising for exploration of a new therapeutic target for RCT disorder and development of innovative agents as well.

\section{ACKNOWLEDGEMENT}

This study was supported by Natural Science Foundation of Guangdong Province, China (grant no. S2013010012360), Guangdong Provincial Department of Science and Technology, China (grant no.2012B040304012, 2012A080800003, 2012A080202016, 2013B060300034, 2014A070705014 and 2015A040404030), Administration of Traditional Chinese Medicine of Guangdong Province (grant no. 20141028, 20151013), and Guangdong Provincial key Laboratory of Research and Development in Traditional Chinese Medicine. The authors thank Hongyi LHY Lin of Faculty of Science, University of New South Wales, Kensington 2033, Australia for valuable discussion and revision.

\section{REFERENCES}

1. Chien IC, Lin CH, Chou YJ, Chou P Increased risk of hyperlipidemia in patients with major depressive disorder: a population-based study. J Psychosom Res 2013; 75: 270-274.

2. Sharma RK, Singh VN, Reddy HK Thinking beyond lowdensity lipoprotein cholesterol: strategies to further reduce cardiovascular risk. Vasc Health Risk Manag 2009; 5: 793-799.

3. Borena $W$, Stocks $T$, Jonsson $H$, Strohmaier $S$, Nagel $G$, Bjorge T, Manjer J, Hallmans G, Selmer R, Almquist $M$, et al. Serum triglycerides and cancer risk in the metabolic syndrome and cancer (Me-Can) collaborative study. Cancer Causes Control 2011; 22: 291-299.

4. Hwang YC, Jee JH, Oh EY, Choi YH, Lee MS, Kim KW, Lee MK Metabolic syndrome as a predictor of cardiovascular diseases and type 2 diabetes in Koreans. Int J Cardiol 2009; 134: 313-321.

5. Vijayakrishnan R, Kalyatanda G, Srinivasan I, Abraham GM Compliance with the Adult Treatment Panel III guidelines for hyperlipidemia in a resident-run ambulatory clinic: a retrospective data analysis. J Clin Lipidol 2013; 7: 43-47.

6. Jacobson TA, Miller M, Schaefer EJ Hypertriglyceridemia and cardiovascular risk reduction. Clin Ther 2007; 29: 763-777.

7. Huang $C$, Cen $C$, Wang $C$, Zhan $H$, Ding $X$ Synergistic effects of colchicine combined with atorvastatin in rats with hyperlipidemia. Lipids Health Dis 2014; 13: 67.

8. Lichtenstein L, Serhan N, Annema W, Combes G, Robaye B, Boeynaems JM, Perret B, Tietge UJ, Laffargue M, Martinez LO Lack of P2Y13 in mice fed a high cholesterol diet results in decreased hepatic cholesterol content, biliary lipid secretion and reverse cholesterol transport. Nutr Metab (Lond) 2013; 10: 67.

9. Rojas B, Ramirez Al, Salazar JJ, de Hoz R, Redondo A, Raposo R, Mendez T, Tejerina T, Trivino A, Ramirez JM Low-dosage statins reduce choroidal damage in hypercholesterolemic rabbits. Acta Ophthalmol 2011; 89: 660-669.

10. Aoki $T$, Yamazaki $H$, Suzuki $H$, Tamaki $T$, Sato $F$, Kitahara $M$, Saito $Y$ Cholesterol-lowering effect of NK104, a 3-hydroxy-3-methylglutaryl-coenzyme A reductase inhibitor, in guinea pig model of hyperlipidemia. Arzneimittelforschung 2001; 51: $197-$ 203.

11. Choi WH, Gwon SY, Ahn J, Jung CH, Ha TY Cooked rice prevents hyperlipidemia in hamsters fed a highfat/cholesterol diet by the regulation of the expression of hepatic genes involved in lipid metabolism. Nutr Res 2013; 33: 572-579.

12. Liu YH, Wu JS, Wang $Z Y, Y u C H$, Ying $H Z$, Xu NY Characteristic, polymorphism and expression distribution of LCAT gene in a Mongolian gerbil model for hyperlipidemia. Exp Mol Pathol 2014; 97: 266-272.

13. Tanaka $Y$, Nagao $K$, Nakagiri $H$, Nagaso $T$, Iwasa $Y$, Mori $H$, Asahina M, Imaizumi K, Sato M Unavailability of liver triacylglycerol increases serum cholesterol concentration induced by dietary cholesterol in exogenously hypercholesterolemic (ExHC) rats. Lipids Health Dis 2014; 13: 19.

14. Jo SP, Kim JK, Lim YH Antihyperlipidemic Effects of Rhapontin and Rhapontigenin from Rheum undulatum in Rats Fed a High-Cholesterol Diet. Planta Med 2014; 80: 1067-1071.

15. Liu Y, Huang $C$, Ceng $C$, Zhan $H$, Zheng D, Han $W$ Metformin enhances nitric oxide production and diminishes Rho kinase activity in rats with hyperlipidemia. Lipids Health Dis 2014; 13: 115.

16. Ko SH, Park JH, Kim SY, Lee SW, Chun SS, Park E Antioxidant Effects of Spinach (Spinacia oleracea L.) Supplementation in Hyperlipidemic Rats. Prev Nutr Food Sci 2014; 19: 19-26.

17. Liu C, Hu MY, Zhang M, Li F, Li J, Zhang J, Li Y, Guo $H F$, Xu P, Liu L, et al. Association of GLP-1 secretion with anti-hyperlipidemic effect of ginsenosides in high-fat diet fed rats. Metabolism 2014; 63: 1342-1351.

18. Wang YC, Lu JM, Jin HZ, Ma AN, Zhang JY, Gong $N$, Xiao $Q$, Zhu B, Lv YF, Yu N, et al. Beneficial effects of 
natural Jeju groundwaters on lipid metabolism in high-fat diet-induced hyperlipidemic rats. Nutr Res Pract 2014; 8: 165-171.

19. Tolani S, Pagler TA, Murphy AJ, Bochem AE, Abramowicz S, Welch C, Nagareddy PR, Holleran S, Hovingh GK, Kuivenhoven JA, et al. Hypercholesterolemia and reduced HDL-C promote hematopoietic stem cell proliferation and monocytosis: studies in mice and FH children. Atherosclerosis 2013; 229: 79-85.

20. Fabbrini E, Magkos F Hepatic Steatosis as a Marker of Metabolic Dysfunction. Nutrients 2015; 7: 4995-5019.

21. Huang WC, Chen YM, Kan NW, Ho CS, Wei L, Chan CH, Huang HY, Huang CC Hypolipidemic effects and safety of Lactobacillus reuteri 263 in a hamster model of hyperlipidemia. Nutrients 2015; 7: 3767-3782.

22. Bennett MK, Ngo TT, Athanikar JN, Rosenfeld JM, Osborne TF Co-stimulation of promoter for low density lipoprotein receptor gene by sterol regulatory elementbinding protein and Sp1 is specifically disrupted by the yin yang 1 protein. J Biol Chem 1999; 274: 1302513032.

23. Shi Y, Guo R, Wang X, Yuan D, Zhang S, Wang J, Yan $X$, Wang $C$ The regulation of alfalfa saponin extract on key genes involved in hepatic cholesterol metabolism in hyperlipidemic rats. PLoS One 2014; 9: e88282.

24. Yiu WF, Kwan PL, Wong CY, Kam TS, Chiu SM, Chan $S W$, Chan $R$ Attenuation of fatty liver and prevention of hypercholesterolemia by extract of Curcuma longa through regulating the expression of CYP7A1, LDLreceptor, HO-1, and HMG-CoA reductase. J Food Sci 2011; 76: H80-89.

25. Rojo-Arreola L, Long $T$, Asarnow $D$, Suzuki BM, Singh R, Caffrey CR Chemical and genetic validation of the statin drug target to treat the helminth disease, schistosomiasis. PLoS One 2014; 9: e87594. 